\title{
Computer models in problems of ensuring electromagnetic safety
}

\author{
Natalia V. Buyakova ${ }^{1, *}$, Andrey V. Kryukov ${ }^{2,3}$, Dmitriy A. Seredkin ${ }^{3,}$, and Le Van Thao ${ }^{2}$. \\ ${ }^{1}$ Angarsk State Technical University, 665835, Angarsk, Russia \\ ${ }^{2}$ Irkutsk State Transport University, 664074, Irkutsk, Russia \\ ${ }^{3}$ Irkutsk National Research Technical University, 664074, Irkutsk, Russia
}

\begin{abstract}
In the process of the smart grids formation a special attention is started to be paid to the issues of power engineering facilities safe functioning and reduction in their negative impact on personnel and environment. One of the important factors of such an impact is the generation of significant levels of strength of electromagnetic fields (EMF) by high-voltage overhead power transmission lines (OPL). In the context of the electric power industry digitalization, in order to improve the electromagnetic safety of service personnel, development of methods and means for digital modeling of EMF created by power lines of various designs is required, including traction networks of electrified railways. Computer models providing an adequate determination of the OPL EMF can be implemented on the basis of methods and tools designed for determining the parameters of the modes of electric energy systems in phase coordinates, developed at the Irkutsk State University for Railroads Communications. As an example of using these methods, the solution to the problem of constructing pictures of the distribution of EMF in the space surrounding the intersection of a flexible symmetrical conductor and a $25 \mathrm{kV}$ traction network is given.
\end{abstract}

\section{Introduction}

The transition to digital technologies carried out in the electric power industry [1] nowadays requires the implementation of new approaches to computer models of electric energy systems (EES), which provide the complexity of modeling along with adequacy and accuracy.

One of these approaches is being developed at Irkutsk State Transport University and is based on mathematical models of EES modes, implemented in phase coordinates [2].

The complexity of the developed models consists in the possibility of solving on their basis a wide range of problems arising in the design and operation of EES: determination of normal and emergency modes, parametric identification of power lines and transformers, modeling of ice melting processes, assessment of electromagnetic safety conditions (EMS) [3-9].

Below are the results of determining the EMS conditions at the inter-section of a flexible symmetrical electrical pathway (SEP) $10 \mathrm{kV}$ [10] (fig. 1) and $25 \mathrm{kV}$ traction network (TN) of electrified railroad (fig. 2).

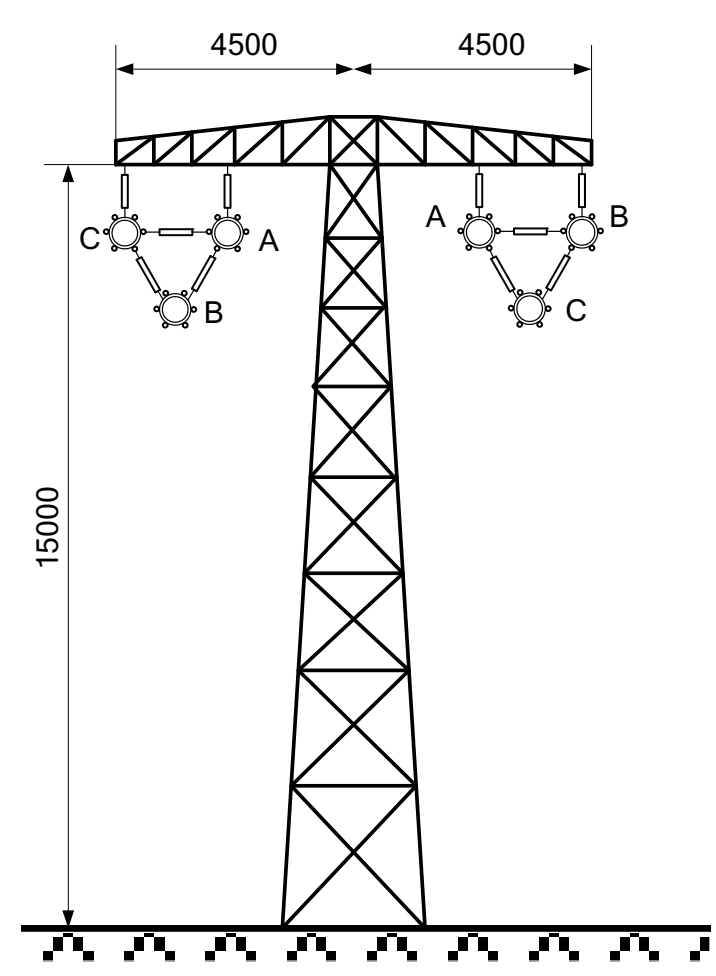

a)

\footnotetext{
${ }^{*}$ Corresponding author: bn_900@mail.ru
} 


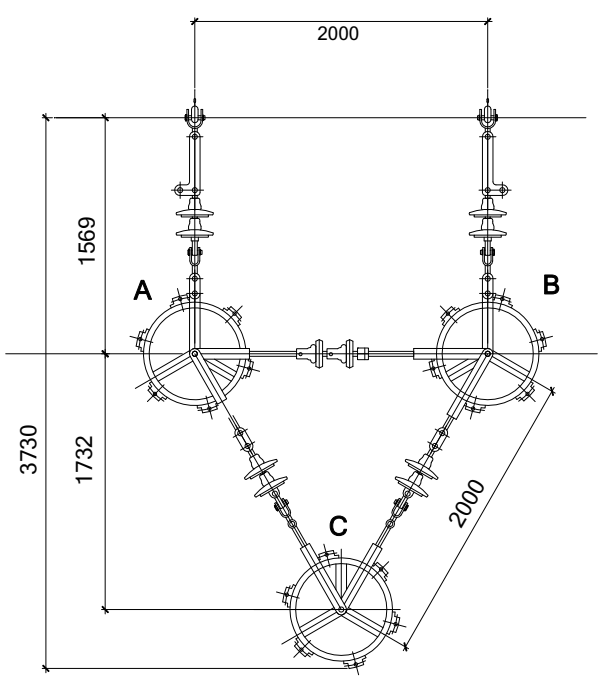

b)

Fig. 1. Support (a) of a symmetrical electrical pathway and design (b) of conductive parts

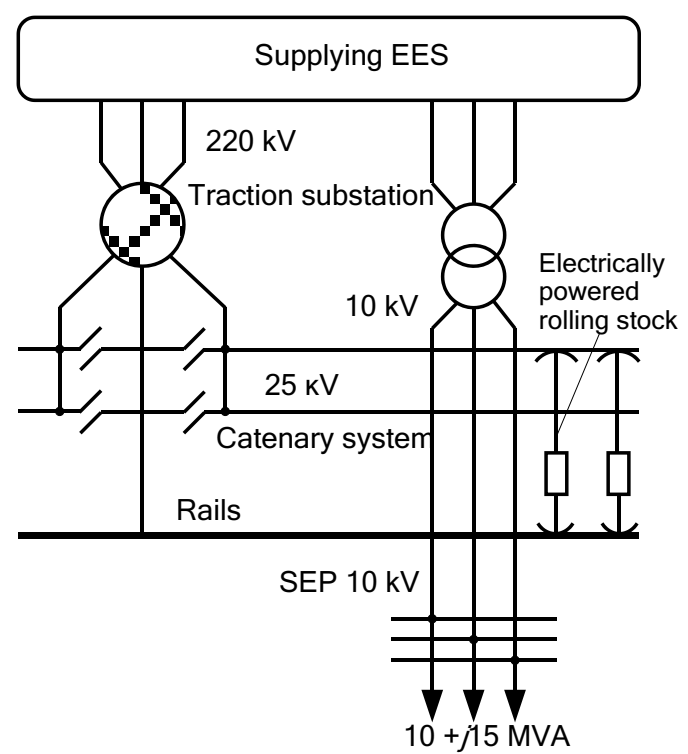

Fig. 2. Diagram of TN and SEP

\section{Computer models for analyzing EMS conditions at the intersection of traction networks and OPL}

EMS conditions are determined by the levels of EMF strengths [11-21], which are usually calculated at a standard height of $1.8 \mathrm{~m} \mathrm{[22].} \mathrm{To} \mathrm{determine} \mathrm{the} \mathrm{strengths}$ at the intersection points of OPL and $\mathrm{TN}$, the algorithm [17] is used, which includes the phases shown in fig. 3.

Due to the electromagnetic imbalance, AC traction networks create relatively large electric and magnetic fields. Increase in trains speeds results in the increase in current amounts consumed by the rolling stock and the higher levels of magnetic field strengths and the higher levels of magnetic field strengths which requires an additional analysis of electromagnetic safety conditions. However, in points of overhead power lines and railroad intersection, traction network electromagnetic fields and overhead power lines interfere with each other which can result in increase in strengths and complication of the field spatial structure.

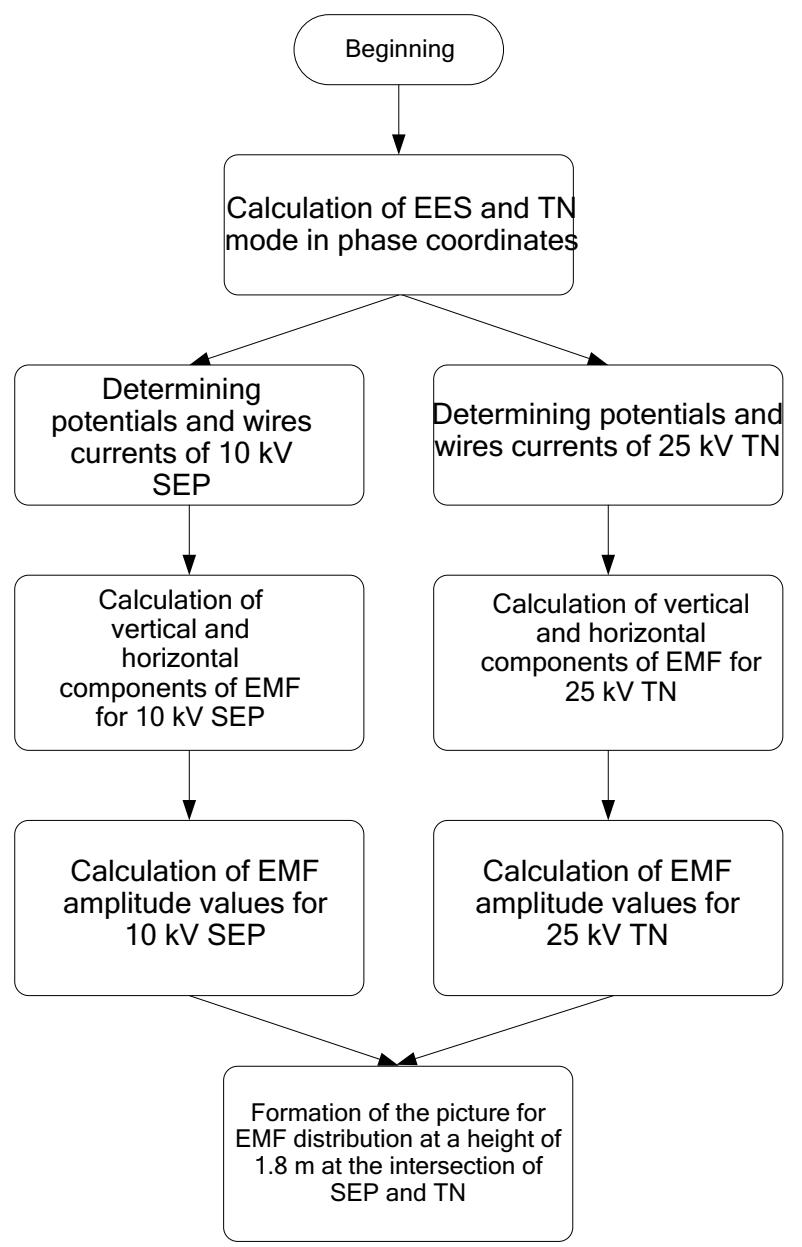

Fig. 3. Algorithm electromagnetic safety conditions analysis

Digital models for analyzing electromagnetic safety conditions at the intersection of power lines and $\mathrm{TN}$ are formed as two systems of nonlinear equations written on the basis of phase coordinates

$$
\mathbf{F}_{1}\left(\mathbf{S}^{(1)}, \mathbf{V}^{(1)}\right)=\mathbf{0} ; \mathbf{F}_{2}\left(\mathbf{S}^{(2)}, \mathbf{V}^{(2)}\right)=\mathbf{0},
$$

where $\mathbf{F}_{k}, k=1,2$ - non-linear vector-functions; $\mathbf{S}^{(k)}, \mathbf{V}^{(k)}$ - accordingly uncontrolled and controlled mode parameters. Index $k$, equal to one, corresponds to onephase TN, and $k=2-$ to three-phase OPL.

Based on parameters found from equations (1) solution $\mathbf{S}^{(k)}, k=1,2$ vertical and horizontal components of electric and magnetic fields [17] are determined for a preset set of $x, y$ spatial coordinates; in addition, amplitude values of voltages are calculated. Based on methods described in works [17, 20], algorithm for obtaining of EMF voltage components is formed in the intersection point

$$
\begin{aligned}
& \mathbf{\Xi}_{E}: \mathbf{E}_{X}^{(1)}, \mathbf{E}_{Y}^{(1)}, \mathbf{E}_{X}^{(2)}, \mathbf{E}_{Y}^{(2)} \rightarrow \mathbf{E}_{X}^{(\Sigma)}, \mathbf{E}_{Y}^{(\Sigma)} \\
& \mathbf{\Xi}_{H}: \mathbf{H}_{X}^{(1)}, \mathbf{H}_{Y}^{(1)}, \mathbf{H}_{X}^{(2)}, \mathbf{H}_{Y}^{(2)} \rightarrow \mathbf{H}_{X}^{(\Sigma)}, \mathbf{H}_{Y}^{(\Sigma)},
\end{aligned}
$$


where $\boldsymbol{\Xi}_{E}, \boldsymbol{\Xi}_{H}-$ operators; index $E$ refers to electrical field, while index $H$ - to magnetic; $\mathbf{E}_{X}^{(1)}, \mathbf{E}_{Y}^{(1)}, \mathbf{E}_{X}^{(2)}, \mathbf{E}_{Y}^{(2)}-$ sets of spatial components of electric field strengths corresponding to a set of coordinates $x, y$; $\mathbf{H}_{X}^{(1)}, \mathbf{H}_{Y}^{(1)}, \mathbf{H}_{X}^{(2)}, \mathbf{H}_{Y}^{(2)}$ - the same for the magnetic field; $\mathbf{E}_{X}^{(\Sigma)}, \mathbf{E}_{Y}^{(\Sigma)}$ - components of the resulting electric field strengths; $\mathbf{H}_{X}^{(\Sigma)}, \mathbf{H}_{Y}^{(\Sigma)}$ - the same for the magnetic field.

Using technique proposed in $[17,20]$ EMF strengths amplitude values are determined

$$
\begin{gathered}
\Theta_{E} \mathbf{E}_{X}^{(\Sigma)}, \mathbf{E}_{Y}^{(\Sigma)}: \rightarrow \mathbf{E}_{X}^{(\max )}, \mathbf{E}_{Y}^{(\max )} ; \\
\Theta_{H}: \mathbf{H}_{X}^{(\Sigma)}, \mathbf{H}_{Y}^{(\Sigma)} \rightarrow \mathbf{H}_{X}^{(\max )}, \mathbf{H}_{Y}^{(\max )} .
\end{gathered}
$$

Below are the results of the analysis of the EMF structure in the place of the perpendicular intersection of the flexible symmetrical electrical pathway and the traction network.

\section{Simulation results}

Simulation was carried out using the Fazonord software package (SWP) [2] in order to obtain a picture of the distribution of EMF strengths at a standard height of 1.8 $\mathrm{m}$ for the intersection point of $25 \mathrm{kV} \mathrm{TN}$ and $10 \mathrm{kV}$ double-circuit SEP with a length of $1.62 \mathrm{~km}$, made with A-600 wires (fig. 1b).

Two mode situations were simulated:

- symmetric operation of a double-circuit SEP with loads of each phase of $10+j 5 \mathrm{MV} \cdot \mathrm{A}$;

- short circuit (SC) of phases $\mathrm{B}$ and $\mathrm{C}$ at the receiving end of the SEP right circuit.

In the both situations considered, the power transit of $8+j 8 \mathrm{MV} \cdot \mathrm{A}$ was carried out along the overhead catenaries of each TN track. The external view of the diagrams of design models implemented in the Fazonord SWP, as well as the spatial arrangement of the conductive parts are shown in fig. 4-6.

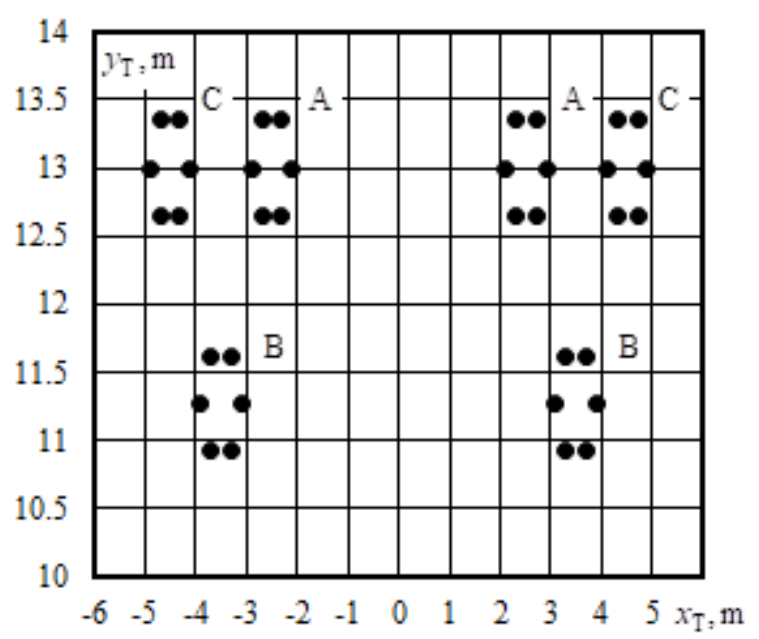

Fig. 4. Spatial coordinates of the conductive parts of the electric pathway

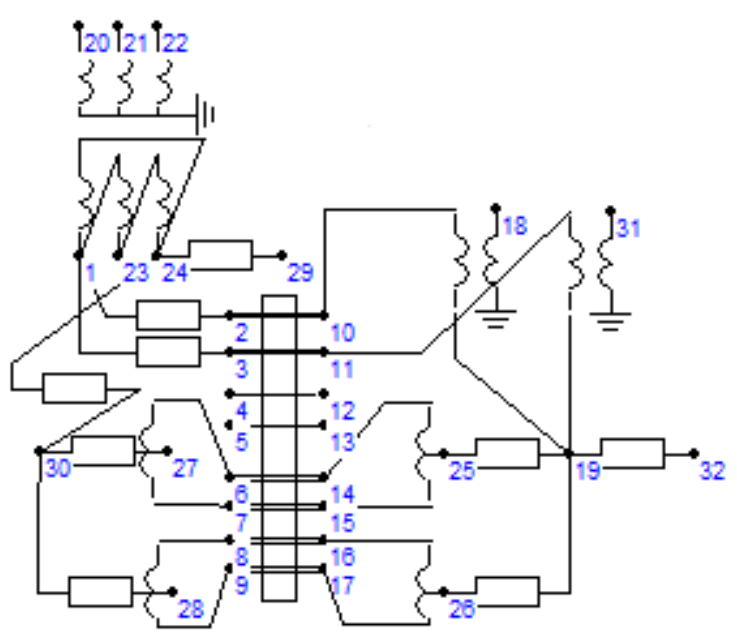

a)

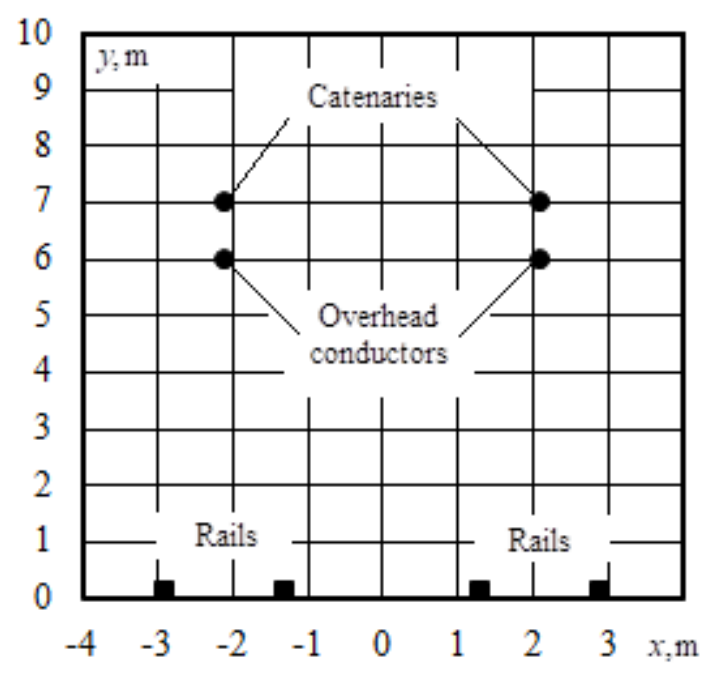

b)

Fig. 5. A design model diagram Fazonord SWP (a) and spatial coordinates of conductive parts (b) of $25 \mathrm{kV} \mathrm{TN}$

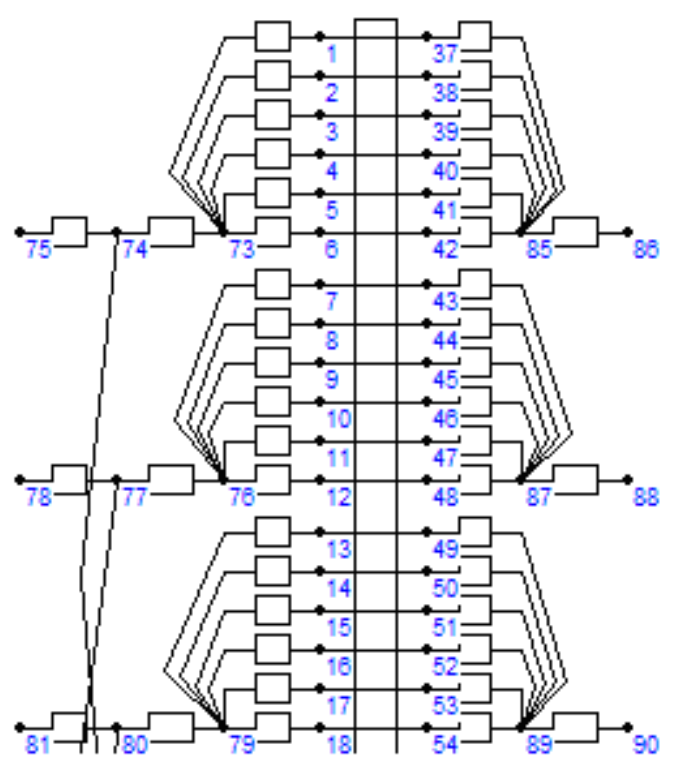

Fig. 6. A fragment of electrical pathway nodalization diagram in Fazonord SWP 
In the Fazonord SWP v. 4.1.04 design models, the algorithms de-scribed above for calculating the TN and SEP modes in phase coordinates, as well as algorithms for determining the EMF strengths in the places of their perpendicular intersection, are implemented.

The results of determining the voltages and currents for the normal mode of the TN and SEP are given in table 1,2 . Table 3 provides summarized data to calculate $\mathrm{SC}$ mode for SEP.

Table 1. Voltages and currents of $25 \mathrm{kV}$ traction network

\begin{tabular}{|c|c|c|c|c|}
\hline \multirow{2}{*}{ Path } & \multicolumn{2}{|c|}{ Voltage } & \multicolumn{2}{c|}{ Currents } \\
\cline { 2 - 5 } & $\mathrm{kV}$ & degr. & $\mathrm{A}$ & degr. \\
\hline 1 & 25.65 & -5.59 & 449.3 & -51 \\
\hline 2 & 25.65 & -5.59 & 449.3 & -51 \\
\hline
\end{tabular}

Table 2. Voltages and currents on receiving ends of electrical pathway right circuit in the normal operating mode

\begin{tabular}{|c|c|c|c|c|}
\hline \multirow{2}{*}{ Phase } & \multicolumn{2}{|c|}{ Voltage } & \multicolumn{2}{c|}{ Currents } \\
\cline { 2 - 5 } & $\mathrm{kV}$ & degr. & $\mathrm{A}$ & degr. \\
\hline $\mathrm{A}$ & 5.75 & -3.3 & 1946.1 & -30 \\
\hline $\mathrm{B}$ & 5.83 & -123 & 1917.5 & -150 \\
\hline $\mathrm{C}$ & 5.79 & 118 & 1931.4 & 91 \\
\hline
\end{tabular}

Table 3. Voltages and currents on receiving ends of electrical pathway right circuit in short circuit mode

\begin{tabular}{|c|c|c|c|c|}
\hline \multirow{2}{*}{ Phase } & \multicolumn{2}{|c|}{ Voltage } & \multicolumn{2}{c|}{ Currents } \\
\cline { 2 - 5 } & $\mathrm{kV}$ & degr. & $\mathrm{A}$ & degr. \\
\hline $\mathrm{A}$ & 5.98 & 0.05 & 0 & - \\
\hline $\mathrm{B}$ & 3.17 & -180 & 27,291 & -172 \\
\hline $\mathrm{C}$ & 2.85 & 179 & 27,291 & 7.9 \\
\hline
\end{tabular}

Results provided in table 1 indicate that phasealigned currents flowing on $\mathrm{TN}$ overhead catenaries contribute to the increase in magnetic field strength. SEP symmetrical mode (table 2) is electromagnetically balanced with currents and voltages phase shifts of $120^{\circ}$. In case of a two-phase short circuit, a significant asymmetry of currents and voltages occurs (table 3 ).

The EMF strengths calculated separately for TN and SEP for different values of the horizontal coordinate are shown in fig. 7 and 8 . They indicate that in the event of separate modeling, the electric field strength for the TN and SEP (fig. 7a, 8a) does not exceed the norms of 5 $\mathrm{kV} / \mathrm{m}$ permissible for electrical personnel.

The TN magnetic field strength exceeds the permissible value of $80 \mathrm{~A} / \mathrm{m}$ (Fig. 6b).

This is due to the electromagnetic imbalance of the $\mathrm{TN}$ and traction loads close to the capacity limit.

A similar parameter for a three-phase $10 \mathrm{kV}$ electrical pathway (fig. $8 \mathrm{~b}$ ) is within the normal range in normal operating mode. In case of a two-phase short circuit, the currents flowing through the individual wires of the SEP reach $5.8 \mathrm{kA}$, which leads to an increase in the voltage to $111 \mathrm{~A} / \mathrm{m}$.

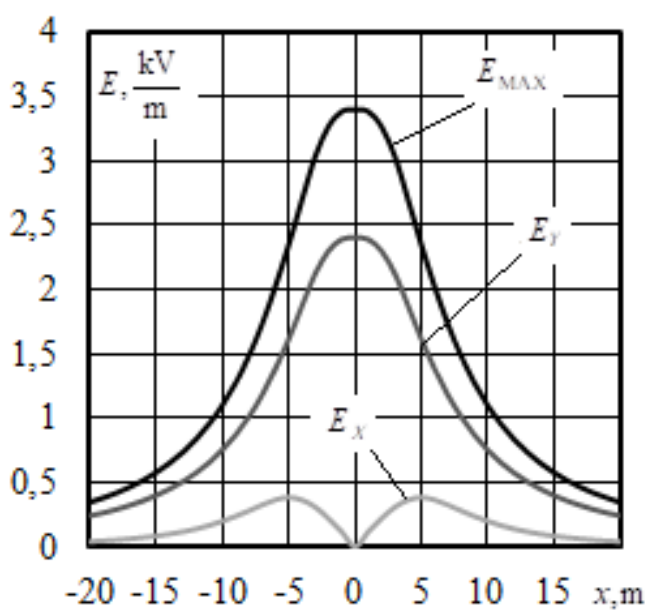

a)

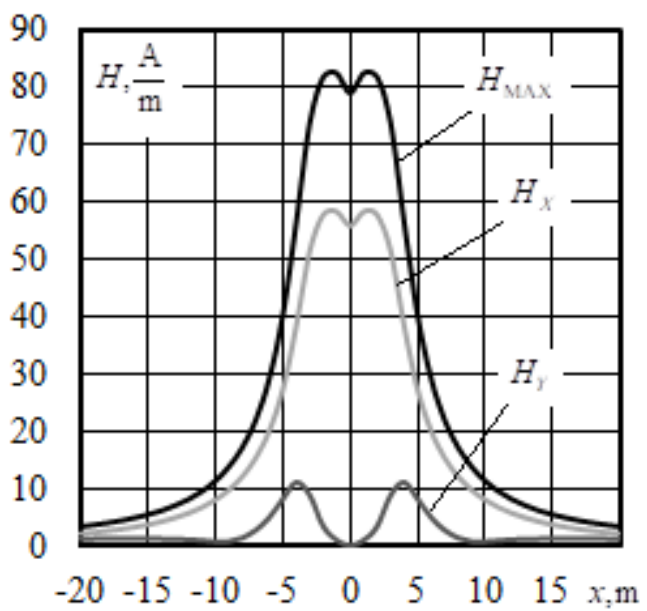

b)

Fig. 7. Electric field (a) and magnetic strengths (b) strengths of $25 \mathrm{kV}$ TN 25

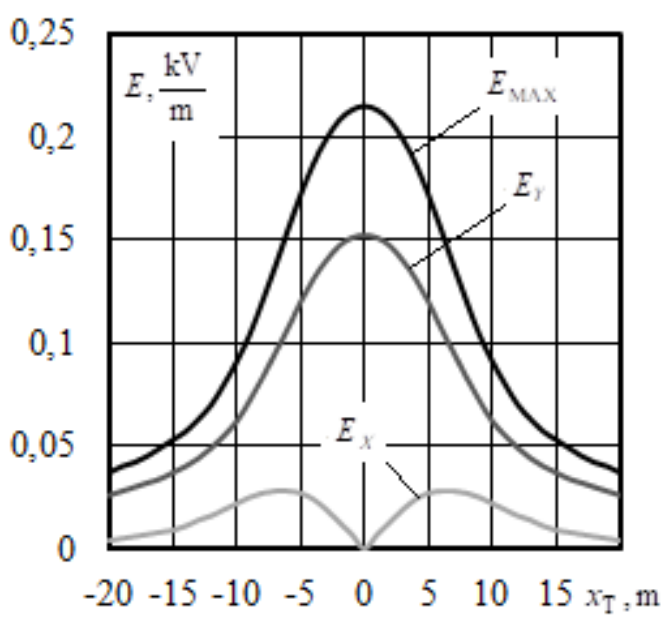

a) 


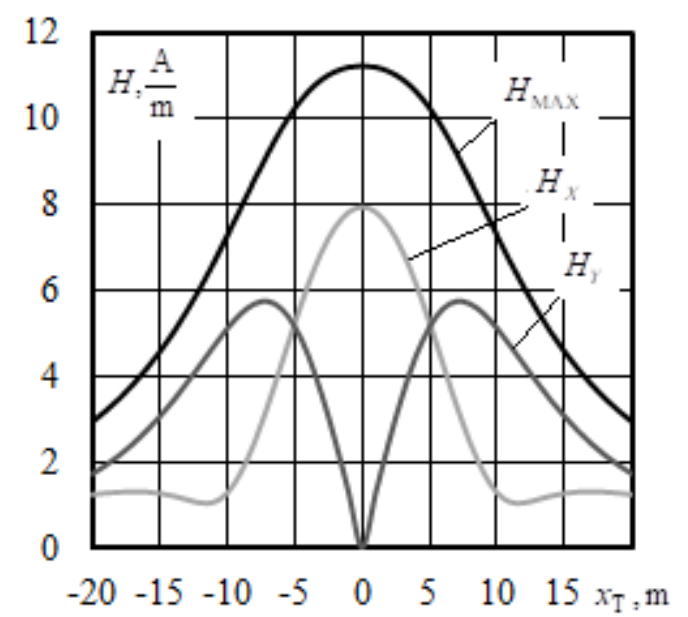

b)

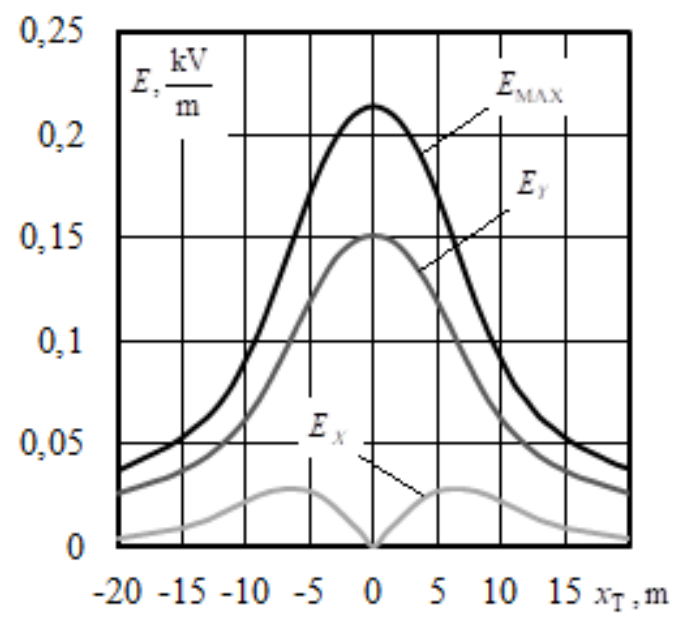

c)

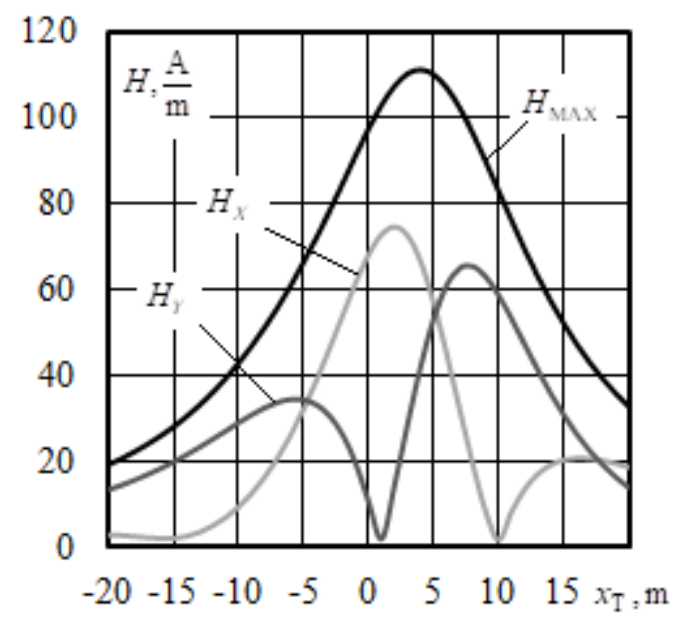

d)

Fig. 8. Strength of electrical (a, c) and magnetic (b, d) fields of SEP: $a, b$ - normal operating mode; $c, d$ - short circuit mode

Volumetric diagrams of the total EMF strengths at the intersection point of the traction network and SEP are provided in fig. 9, 10. Table 4 represents maximal values of electric and magnetic fields strengths at intersection points.

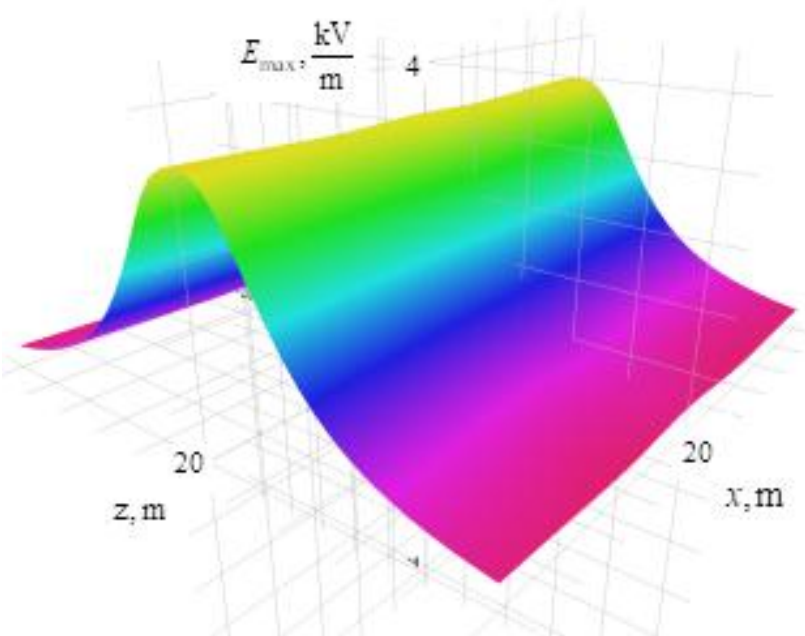

a)

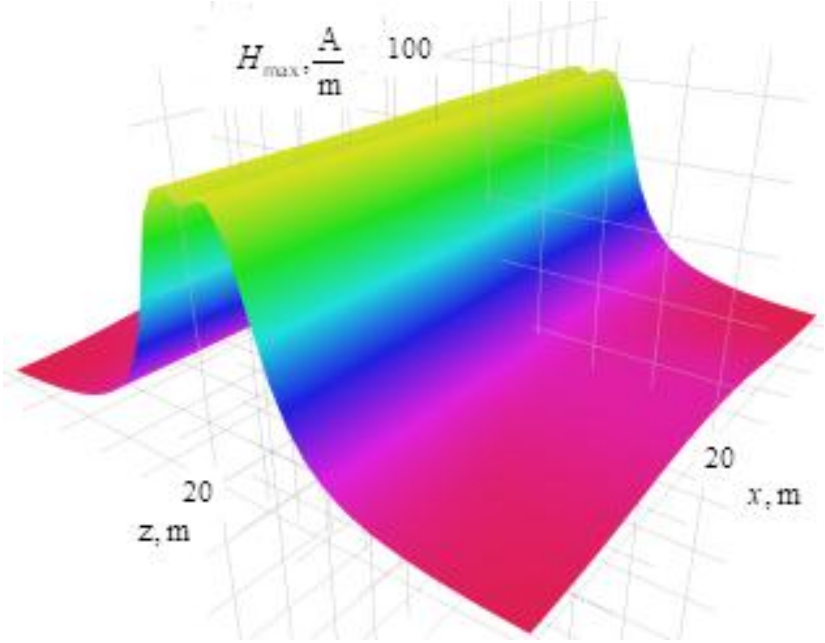

b)

Fig. 9. Amplitude values of EMF strengths at the intersection of the TN and SEP in the normal operating mode: a - electrical field; $b$ - magnetic field

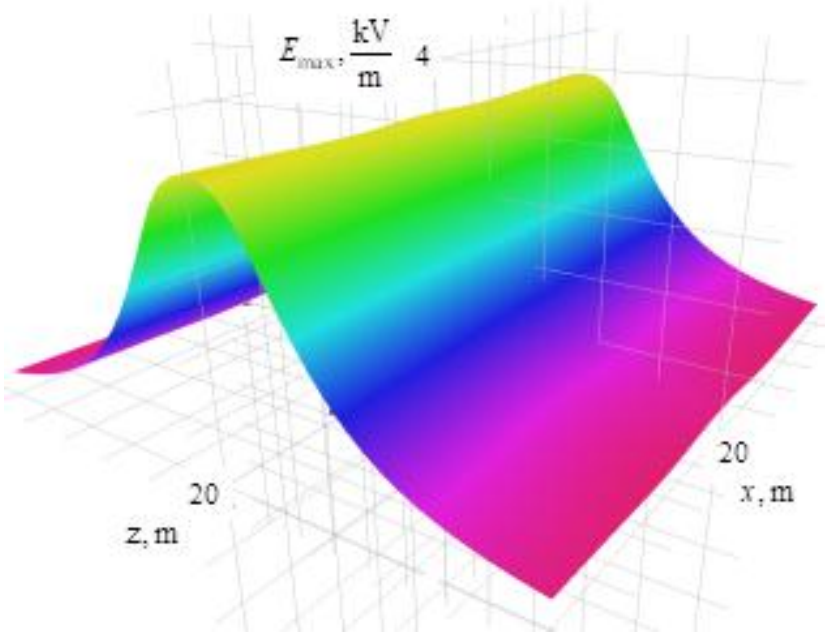

a) 


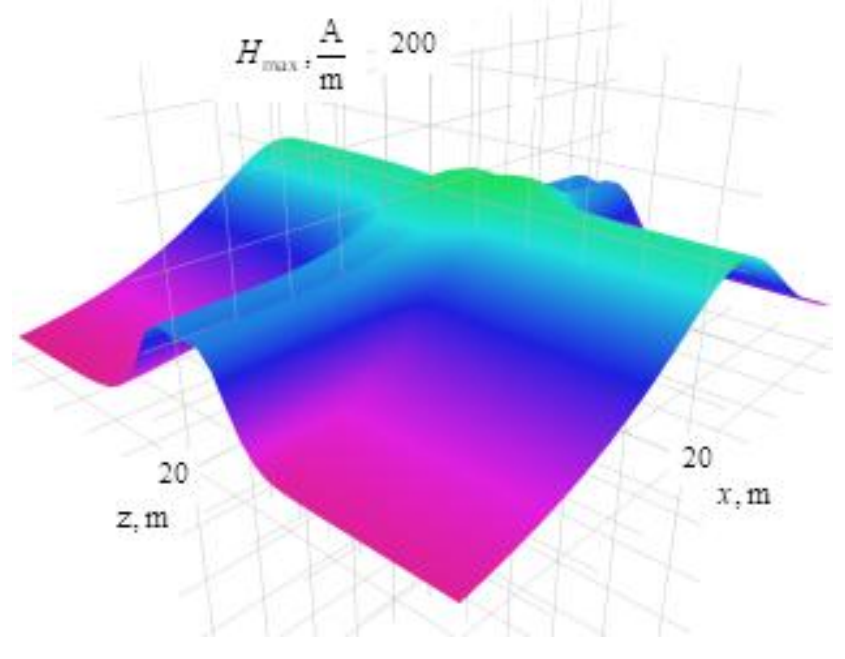

b)

Fig. 10. Amplitude values of EMF strengths at the intersection of the TN and SEP in SC mode: a - electrical field; b magnetic field: $x$ - axis coordinates, directed perpendicular to the TN route; $\mathrm{z}$ - coordinates of the axis directed along the TN route

Table 4. Maximum values of EMF strengths amplitudes

\begin{tabular}{|c|c|c|c|c|}
\hline No. & Facility & Mode & $\begin{array}{c}\max \left(E_{\max }\right), \\
\mathrm{kV} / \mathrm{m}\end{array}$ & $\begin{array}{c}\max \left(H_{\max }\right), \\
\mathrm{A} / \mathrm{m}\end{array}$ \\
\hline 1 & $\begin{array}{c}\text { Traction } \\
\text { networks }\end{array}$ & Normal & 3.39 & 82.6 \\
\hline \multirow{2}{*}{2} & $\begin{array}{c}\text { Electrical } \\
\text { pathway }\end{array}$ & Normal & 0.22 & 11.2 \\
\cline { 3 - 5 } 3 & $\begin{array}{c}\text { TN and SEP } \\
\text { intersection }\end{array}$ & $\begin{array}{c}\text { SC on } \\
\text { electrical } \\
\text { pathway }\end{array}$ & 3.37 & 111.2 \\
\cline { 3 - 5 } & & Normal & 3.37 & 82.6 \\
\hline
\end{tabular}

In normal operation, the strengths of the electric and magnetic fields at the intersection point of TN and SEP differ slightly from similar values for separate simulation. In the short-circuit mode of the electrical pathway, the magnetic field strength at the intersection point increases by $32 \%$ compared to the same indicator for the $\mathrm{TN}$ and reaches $122 \mathrm{~A} / \mathrm{m}$.

Electric and magnetic fields at a height of $1.8 \mathrm{~m}$ at the intersection point of the $\mathrm{TN}$ and the SEP have elliptical polarization.

The presented spatial diagrams can be used in practice to determine the conditions for electromagnetic safety of personnel maintaining the $\mathrm{TN}$ and SEP. It should be noted that similar diagrams can be built for any set of $\boldsymbol{x}, \boldsymbol{y}$ of spatial coordinates.

In particular, when setting $y$ coordinate equal to the height of catenary suspension, diagrams can be obtained that illustrate the safety conditions when servicing the overhead system from removable towers. In addition, a picture of the EMF distribution in space can be built, which will be useful when choosing the locations for the
EMF-sensitive electronic sensors and devices designed to monitor the modes of the vehicle and the electrical pathway.

\section{Conclusion}

The above results allow us to conclude that at the intersection points of $25 \mathrm{kV}$ traction network and the symmetrical electrical pathway, the spatial distribution of electromagnetic fields is significantly complicated. In some points of the plane, located at the standard height of $1.8 \mathrm{~m}$, tension levels that go beyond the permissible values are observed.

\section{Acknowledgments}

The research was carried out within the state assignment of the Ministry of Science and Higher Education of Russian Federation on the topic "Improving the quality of electrical energy and electromagnetic safety in power supply systems of railways equipped with Smart Grid devices by using methods and means of mathematical modeling based on phase coordinates."

\section{References}

1. A. B. Loskutov. Intellectual electrical engineering 1, 9 (2018)

2. V. P. Zakaryukin, A. V. Kryukov, Complex asymmetrical modes of electrical systems (Irkutsk, 2005)

3. A. I. Sidorov, I. S. Okrainnaya, Electromagnetic fields near ultrahigh-voltage electrical installations (Chelyabinsk, 2008)

4. N.V. Byakova, V.P. Zakaryukin, A.V. Kryukov, Electromagnetic safety in railroads power supply systems: modeling and control (Angarsk, 2018)

5. A. B. Kosarev, B. I. Kosarev, Basics of electromagnetic safety of railroad transport power supply systems (Moscow, 2008)

6. S. M. Apollonsky, T. V. Kalyada, B. E. Sindalovsky, Human life safety in electromagnetic fields (St. Petersburg, 2006)

7. S. M. Apolonsky, A. N. Gorsky, Electromagnetic fields calculations (Moscow, 2006)

8. A.A. Ustinov, Improving the efficiency of energy production and use in Siberia, 517 (2005).

9. N. B. Rubtsova, M. Sh. Misrikhanov, V. N. Sedunov, A. Yu. Tokarsky, Bulletin of Samara Research Center of RAN 5(3), 839 (2012)

10. A. M. Semchinov. Electrical pathways of industrial enterprises (London, 1982)

11. R. Kircher, J. Klühspies, R. Palka et al, Transportation Systems and Technology 4(2), 152 (2018)

12. A. Ogunsola, A. Mariscotti, Electromagnetic Compatibility in Railways (London, 2013) 
13. A. Ogunsola, U. Reggiani, L. Sandrolini, EMC'09, 567 (2009)

14. F. Sheilah, Railway Electrification Systems \& Engineering (Delhi 2012)

15. A. R. Zakirova, Zh. M. Bukanov, Bulletin of the Ural State University for railroads communication 2 , 73 (2016)

16. A. R. Zakirova, Protection of electrical personnel against harmful effect of electromagnetic fields (Ekaterinburg, 2018)

17. V. P. Zakaryukin, A. V. Kryukov, Transport infrastructure of Siberian region, 641 (2018)

18. V. P. Zakaryukin, A. V. Kryukov, N.V. Buyakova, The power grid of the future, 39 (2013)
19. N. Buyakova, V. Zakarukin, A. Kryukov, Advances in Intelligent Systems Research 158, 20 (2018)

20. N. V. Buyakova, V. P. Zakaryukin, A.V. Kryukov International Scientific Electric Power Conference, 643 (2019)

21. N. V. Buyakova, V. P. Zakaryukin, A. V. Kryukov, Advances in Engineering Research 158, 219 (2018)

22. Interstate standard. GOST 12.1.002-84. Occupational safety standards system. Industrial frequency electric fields. Allowable strength levels and requirements for monitoring at workplaces (Moscow, 2009) 